\title{
Desert Wetlands-Archives of a Wetter Past
}

Scientists from the U.S. Geological Survey (USGS) are finding evidence of a much wetter past in the deserts of the American Southwest using a most unlikely source-wetlands. Wetlands form in arid environments where water tables approach or breach the ground surface. Often thought of as stagnant and unchanging, new evidence suggests that springs and wetlands responded dynamically to past episodes of abrupt climate change. Multiple cycles of deposition, erosion, and soil formation show that wetlands in the southwestern United States expanded and contracted many times during the past 35,000 years or so, before disappearing altogether as the last glacial period came to a close. USGS scientists are now studying the deposits to determine how closely conditions in the desert were tied to regional and global climate patterns in the past, and what it might mean for the fragile ecosystems in light of anticipated climate change in the future.

\section{Wetlands in the Geologic Record}

As continental ice sheets waxed and waned during the late Pleistocene, global reorganizations of the atmosphere, biosphere, and hydrosphere resulted in dramatic physical changes in the deserts of the American Southwest. Plant communities were often displaced 1,000 meters or more downslope, perennial lakes were present where only dry playas exist today, and large animals (megafauna) lived in areas that are now too hot and dry to support them. The cooler, wetter conditions of the late Pleistocene also supported higher groundwater levels in the desert, which fed extensive networks of marshes, wet meadows, seeps, and flowing springs in many low-lying valleys and basins.

In wetland settings, eolian, alluvial, and fluvial sediments are trapped by a combination of wet ground conditions and dense plant cover. Over time, these sediments build up and are ultimately preserved in the geologic record as a unique combination of clastic sediments, chemical precipitates, and organic matter that are collectively called "paleowetland deposits" (fig. 1). Paleowetland deposits contain information on the timing and magnitude of past changes in watertable levels and, therefore, can be important sources of hydrologic and climatic information.

Traditionally, geologists have relied heavily on lake deposits to reconstruct the magnitude and timing of environmental changes that took place in the American Southwest. Wetland deposits contain complementary information to

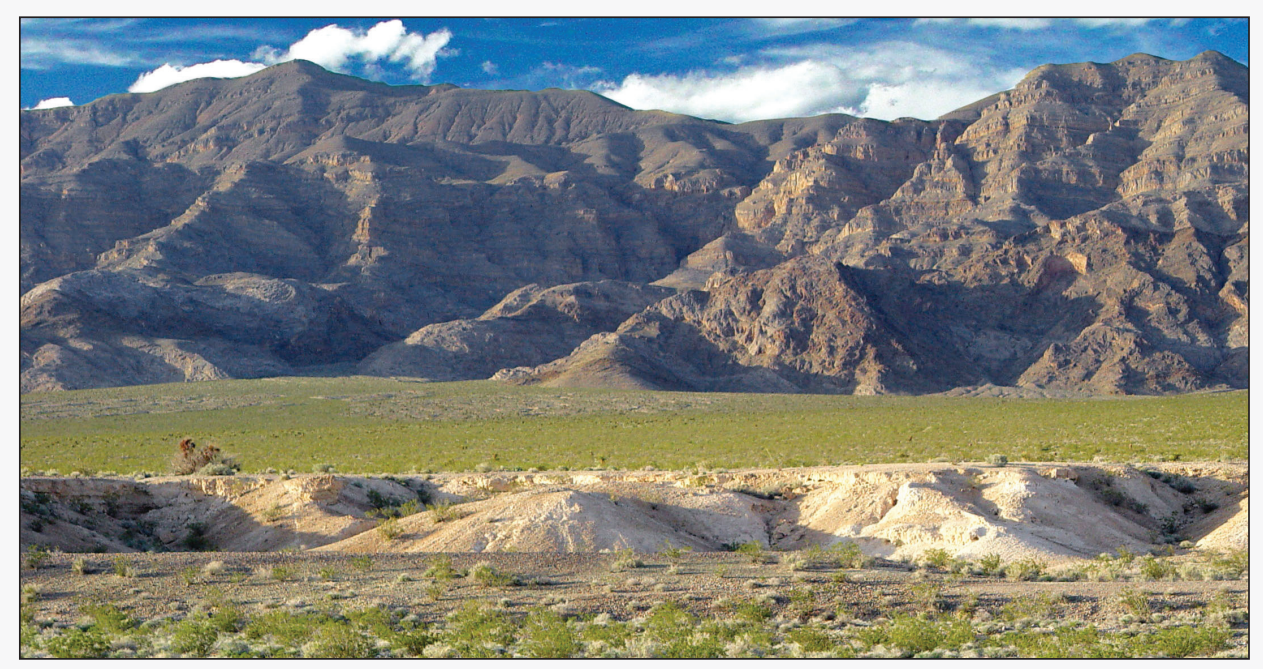

Figure 1. In southern Nevada, buff-colored deposits sit against the backdrop of the Las Vegas Range just outside the city limits of Las Vegas. Once thought to be remnants of a large lake, these deposits actually record the presence of extensive wetlands that were home to an array of Pleistocene megafauna. They also hold valuable clues to understanding how desert ecosystems responded to climate change in the past. (Photograph courtesy of Eric Scott.)

lakes and offer several advantages. First, they provide unequivocal evidence of past water-table levels. In many instances, the elevation of past discharge can be identified to within a few centimeters. Second, they are often exposed over fairly large areas, which affords researchers the opportunity to examine and interpret complex sedimentological features that can be missed in sediment cores. Third, they can be dated by multiple techniques and, therefore, hydrologic and climatic conditions recorded by wetlands can be tied directly to other climate records, such as ice cores, marine and lake sediments, and speleothems (cave deposits). Finally, they are relatively common in the world's arid lands and can be used to reconstruct past conditions on a variety of spatial and temporal scales.

Wetland deposits are also important archeological and paleontological archives. Active wetlands provide reliable sources of fresh water in an otherwise arid landscape and thus act as focal points for human and faunal activities. The remains of large vertebrates are frequently preserved in wetland deposits, which allows researchers to examine how faunal communities responded to past episodes of climate change in arid environments, as well as to investigate potential ties between megafauna extinctions, changes in past environmental conditions, and the arrival of humans. 


\section{Dr. C. Vance Haynes, Jr. and the birth of desert wetland research}

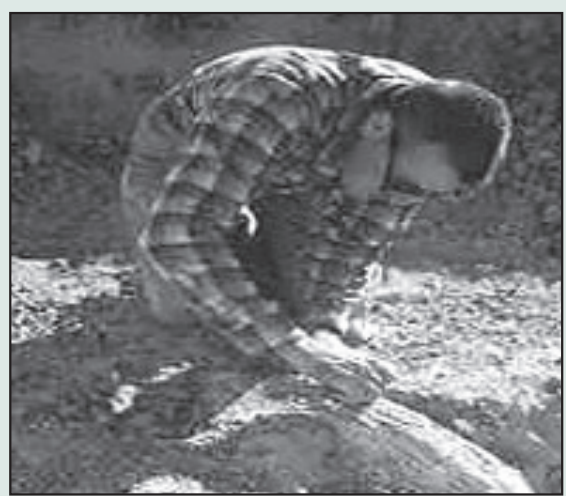

Dr. C. Vance Haynes, Jr., at the Tule Springs archeological site near Las Vegas. (Photograph courtesy of San Bernardino County Museum.)
Renowned for his pioneering work on the peopling of North America, Dr. C. Vance Haynes, Jr., is also the godfather of desert wetland research in the southwestern United States. In 1962, he began studies of wetland deposits at the Tule Springs archeological site located in the Upper Las Vegas Wash to understand what drew the ancient people to the area, how they survived in southern Nevada's arid conditions, and whether they coexisted with Pleistocene megafauna. Nearly a half-century later, USGS scientists continue to refine the geologic and chronologic frameworks that Dr. Haynes established.

\section{Ecosystem Response to Climate Change in the Las Vegas Valley}

Today, a harsh desert landscape surrounds the city of Las Vegas. Boasting extreme temperatures and dry weather for much of the year, Las Vegas was founded in the mid-19th century near a small set of springs and marshes that provided a continuous source of water to early residents. In prehistoric times, the marshes, or "meadows" for which the city is named, were far more extensive and covered much of the valley. The marshes were also home to some of North America's earliest human inhabitants, as well as a diverse assemblage of Pleistocene megafauna, including mammoth, sloth, bison, camel, horse, and even American lion and sabretoothed cat.

Early scientific work in Las Vegas Valley focused largely on the archeological sites that are prevalent in the area. More recently, a collaborative effort between the USGS and San Bernardino County Museum (SBCM), with funding by the Bureau of Land Management, has focused on investigating paleowetland deposits in the Upper Las Vegas Wash, located just outside the city limits. There, SBCM scientists discovered and excavated hundreds of fossil sites in what is now Tule Springs Fossil Beds National Monument. In support of these efforts, USGS scientists have helped refine the stratigraphy and chronology of the Las Vegas Valley paleowetland deposits in order to place the fossils in a firm geologic context, and to understand how the hydrologic systems responded to climate change in the past.

The results of the investigations show that wetlands in the Las Vegas Valley expanded and contracted many times in response to changing climate conditions during the late Pleistocene (fig. 2). Cessation of groundwater discharge associated with rapid warming events resulted in the collapse of entire wetland systems at multiple times during the late Quaternary. Drought-like conditions in the valley, as recorded by widespread erosion and the formation of desert soils, typically lasted for a few centuries, which illustrates the potential vulnerability of these fragile ecosystems to climate change.

USGS scientists are currently investigating wetland deposits elsewhere in the southern Great Basin and Mojave Deserts to determine how water tables responded to past changes in climate on a regional scale. Information yet to be discovered could help answer critical questions about how these ecosystems might behave in the future. The results may also have profound implications for those managing active springs and wetlands today, as they are often home to threatened and endangered species living in the deserts of the American Southwest.

—By Jeffrey S. Pigati, Kathleen B. Springer, Craig R. Manker

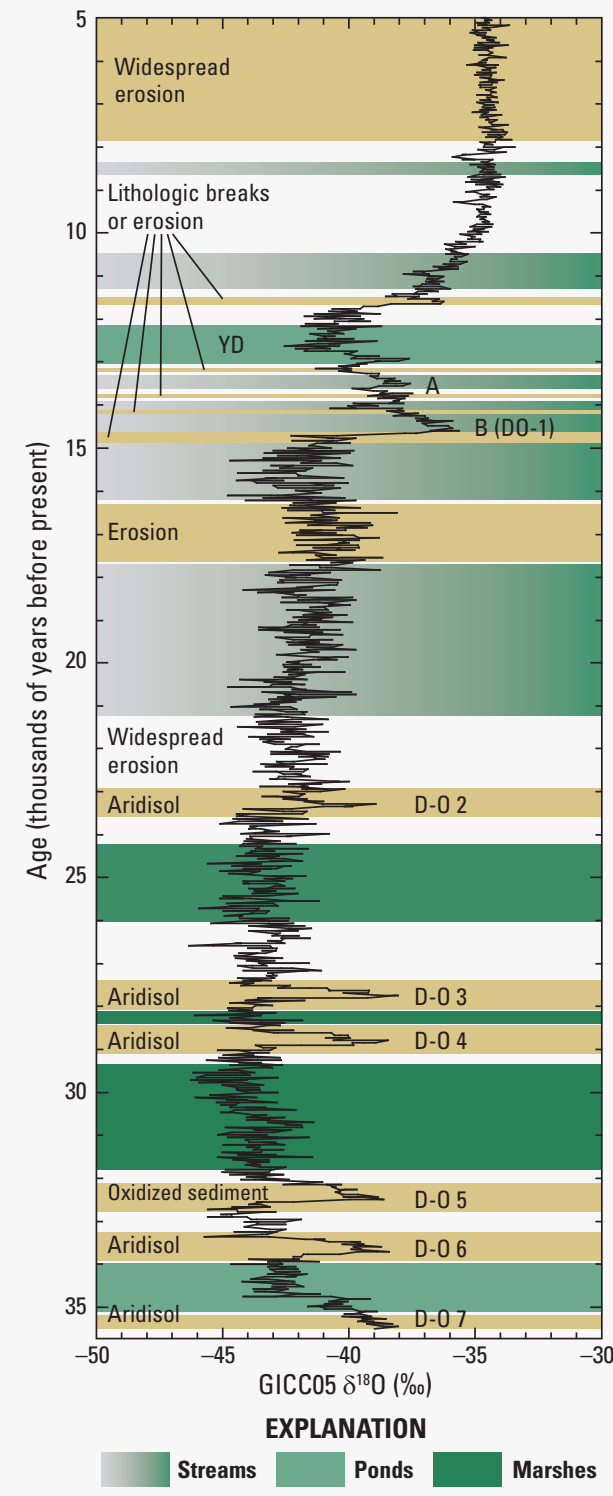

Figure 2. Types of groundwater discharge in the Las Vegas Valley compared to isotopic values from the Greenland ice core record (higher isotopic values to the right represent warmer conditions; lower values represent cooler conditions). Wetland expansion and contraction in the Las Vegas Valley marched in virtual lockstep with short-lived, northern hemispheric climate oscillations, including Dansgaard-Oeschger (D-O) cycles, the Bølling (B) and Allerød (A) warm periods, and the Younger Dryas cold event (YD).

\section{For more information contact:}

U.S. Geological Survey Geosciences and Environmental Change Science Center http://gec.cr.usgs.gov/ Paleohydrology of Desert Wetlands project This fact sheet is available online at http://dx.doi.org/10.3133/fs20153077 